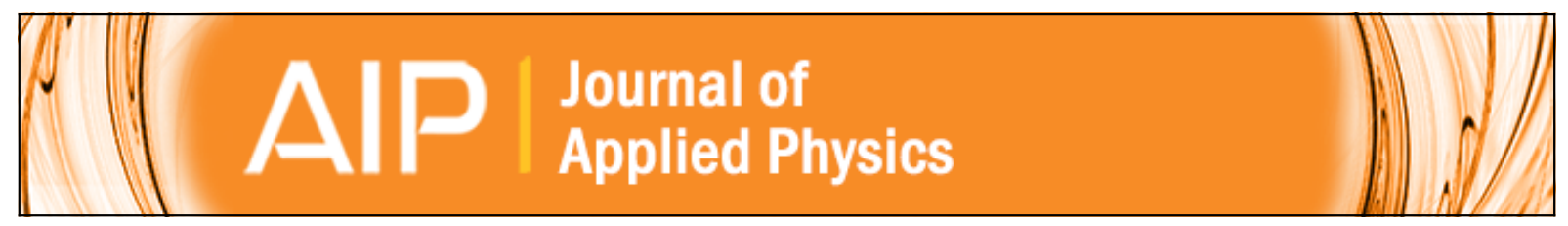

\title{
Ultrafast trapping times in ion implanted InP
}

C. Carmody, H. Boudinov, H. H. Tan, C. Jagadish, M. J. Lederer, V. Kolev, B. Luther-Davies, L. V. Dao, and M. Gal

Citation: Journal of Applied Physics 92, 2420 (2002); doi: 10.1063/1.1493651

View online: http://dx.doi.org/10.1063/1.1493651

View Table of Contents: http://scitation.aip.org/content/aip/journal/jap/92/5?ver=pdfcov

Published by the AIP Publishing

\section{Articles you may be interested in}

Ion channeling effects on quantum well intermixing in phosphorus-implanted InGaAsP / InGaAs/InP J. Appl. Phys. 98, 054904 (2005); 10.1063/1.2033143

Structural, electrical, and optical analysis of ion implanted semi-insulating $\ln P$ J. Appl. Phys. 95, 477 (2004); 10.1063/1.1633349

Ultrafast carrier trapping and recombination in highly resistive ion implanted InP J. Appl. Phys. 94, 1074 (2003); 10.1063/1.1576516

Ion-implanted In $0.53 \mathrm{Ga} 0.47$ As for ultrafast optoelectronic applications Appl. Phys. Lett. 82, 3913 (2003); 10.1063/1.1579565

Activation of electrical carriers in Zn-implanted InP by low-power pulsed-laser annealing J. Appl. Phys. 82, 5334 (1997); 10.1063/1.366300

\section{AIP $\left.\right|_{\text {APL Photonics }}$}

APL Photonics is pleased to announce Benjamin Eggleton as its Editor-in-Chief

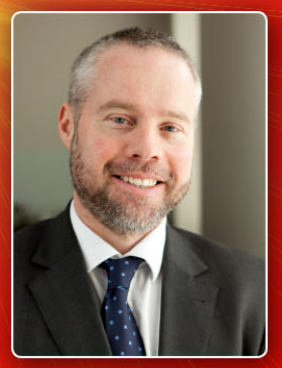




\title{
Ultrafast trapping times in ion implanted InP
}

\author{
C. Carmody, ${ }^{\text {a) }}$ H. Boudinov, ${ }^{\text {b) }}$ H. H. Tan, and C. Jagadish \\ Department of Electronic Materials Engineering, Research School of Physical Sciences and Engineering, \\ The Australian National University, Canberra, ACT 0200, Australia \\ M. J. Lederer, V. Kolev, and B. Luther-Davies \\ Laser Physics Centre, Research School of Physical Sciences and Engineering, The Australian National \\ University, Canberra, ACT 0200, Australia
}

L. V. Dao and M. Gal

School of Physics, University of New South Wales, Sydney, NSW, 2052, Australia

(Received 13 August 2001; accepted for publication 20 May 2002)

\begin{abstract}
$\mathrm{As}^{+}$and $\mathrm{P}^{+}$implantation was performed on semi-insulating (SI) and $p$-type InP samples for the purpose of creating a material suitable for ultrafast optoelectronic applications. SI InP samples were implanted with a dose of $1 \times 10^{16} \mathrm{~cm}^{-2}$ and $p$-type InP was implanted with doses between 1 $\times 10^{12}$ and $1 \times 10^{16} \mathrm{~cm}^{-2}$. Subsequently, rapid thermal annealing at temperatures between 400 and $700{ }^{\circ} \mathrm{C}$ was performed for $30 \mathrm{sec}$. Hall-effect measurements, double-crystal $\mathrm{x}$-ray diffraction, and time-resolved femtosecond differential reflectivity showed that, for the highest-annealing temperatures, the implanted SI InP samples exhibited high mobility, low resistivity, short response times, and minimal structural damage. Similar measurements on implanted $p$-type InP showed that the fast response time, high mobility, and good structural recovery could be retained while increasing the resistivity. (C) 2002 American Institute of Physics. [DOI: 10.1063/1.1493651]
\end{abstract}

\section{INTRODUCTION}

The discovery of ultrafast carrier recombination characteristics in GaAs grown by molecular-beam epitaxy at lowsubstrate temperatures (LT-GaAs) ${ }^{1-3}$ has led to continued research into semiconductor materials for subpicosecond optoelectronic applications. This is due to the fact that LTGaAs has such superior characteristics as short carrier lifetime, high resistivity ( $>10^{5} \Omega \mathrm{cm}$ ), and high-electron mobility. It has been shown recently that ion implantation of GaAs can result in a material with properties similar to those of LT-GaAs. ${ }^{4-6}$ Broad studies made on LT-GaAs have led to the conclusion that non-stoichiometry of this material with a high-arsenic excess in the form of antisite defects and As precipitates is the main reason for high resistivity and fast recombination of photocarriers. ${ }^{7}$

These results have stimulated efforts to understand electrical and structural properties of LT indium phosphide. ${ }^{8}$ It was found that the LT-InP epilayers were highly conductive and that the dominant intrinsic deep level defect was present in concentrations as high as $10^{19} \mathrm{~cm}^{-3} .^{8}$ The mechanism responsible for the $n$-type conductivity has been attributed to an abundant presence of $\mathrm{P}_{\text {In }}$ antisites, introduced during offstoichiometric InP growth at low temperature.

The antisite defects in III-V materials have been intensively studied, and particularly in GaAs, the arsenic antisite is responsible for the semi-insulating behavior. ${ }^{9}$ In InP, the presence of these defects has a different character, creating $n$-type free carriers. ${ }^{8}$

\footnotetext{
a)Electronic mail: cyc109@rsphysse.anu.edu.au



In this article, we have investigated the possibility to achieve high resistivity and ultrashort photoexcited carrier lifetimes in $\mathrm{As}^{+}$- and $\mathrm{P}^{+}$-implanted InP.

\section{EXPERIMENT}

Semi-insulating Fe-doped InP samples were implanted with $\mathrm{As}^{+}$and $\mathrm{P}^{+}$ions at energies of 2 and $1 \mathrm{MeV}$, respectively, at a dose of $1 \times 10^{16} \mathrm{~cm}^{-2}$, and at a substrate temperature of $200{ }^{\circ} \mathrm{C}$. Therefore, damage profiles for both types of implanted species placed the maximum damage at a depth of approximately $1 \mu \mathrm{m}$ from the surface. The amount of damage is expected to be higher for the $\mathrm{As}^{+}$-implanted sample due to the heavier ion mass. P-type epilayers with two different carrier concentrations $\left(\sim 3.4 \mathrm{e} 17\right.$ and $\left.\sim 1.3 \mathrm{e} 18 \mathrm{~cm}^{-3}\right)$ were grown to a thickness of $\sim 1.5 \mu \mathrm{m}$ on semi-insulating InP substrates by metal-organic chemical-vapor deposition, and then implanted under the same conditions to doses between $1 \times 10^{12}$ and $1 \times 10^{16} \mathrm{~cm}^{-2}$. Subsequently, samples were annealed by rapid thermal annealing (RTA) at 400, 500, 600 , and $700{ }^{\circ} \mathrm{C}$ for $30 \mathrm{~s}$ in an Ar atmosphere. Time-resolved femtosecond differential reflectivity of the surface was measured using a standard wavelength-degenerate pump-probe setup. $75 \mathrm{MHz}, 100 \mathrm{fs}$ pulses from a mode-locked Ti:Sapphire laser were tuned to a wavelength of $895 \mathrm{~nm}$, exciting the samples with pump fluences $\left(F_{\text {pump }}\right)$ of 50 or $5 \mu \mathrm{J} \mathrm{cm}^{-2}$. Time-resolved photoluminescence (TRPL) was measured using a femtosecond self-mode locked Ti:sapphire laser. The laser was tunable between 750 and $900 \mathrm{~nm}$, the pulse width was $80 \mathrm{fs}$, the repetition rate $85 \mathrm{MHz}$, and the output power was $200 \mathrm{~mW}$ at $\lambda=780 \mathrm{~nm}$. Double-crystal x-ray diffraction (DCXRD) and Hall-effect measurements (Van der Pauw method $^{10}$ ) were also performed on these samples. 

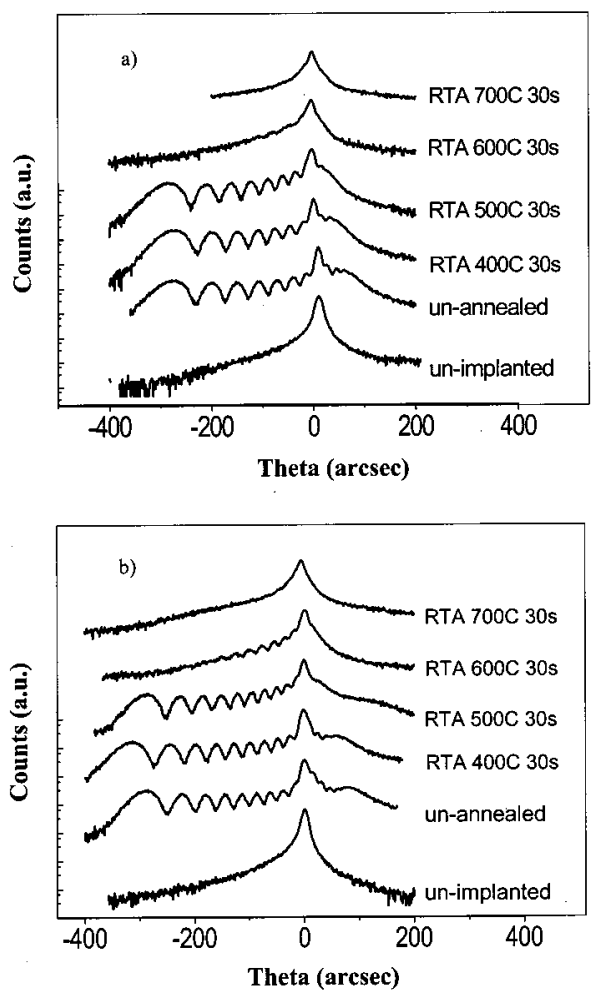

FIG. 1. X-ray rocking curves from InP implanted at $200{ }^{\circ} \mathrm{C}$ with a dose of $1 \times 10^{16} \mathrm{~cm}^{-2} .1 \mathrm{MeV} \mathrm{P}^{+}$(a) and $2 \mathrm{MeV} \mathrm{As}^{+}$(b). Spectra vertically shifted for clarity.

\section{RESULTS AND DISCUSSION}

Figure 1 shows the DCXRD spectra from $s-i$ InP samples implanted with $\mathrm{As}^{+}$and $\mathrm{P}^{+}$to a dose of 1 $\times 10^{16} \mathrm{~cm}^{-2}$. The spectra are markedly different to those obtained by $\mathrm{As}^{+}$ion implantation into GaAs for the same dose: ${ }^{11}$ for those samples which were unannealed or annealed at or below $500{ }^{\circ} \mathrm{C}$, there are periodic fringes on the negative angle side of the rocking curves. These fringes have been associated with a region of positive strain (expansion) created by implantation. Additional features can also be seen on the positive angle side of the main peak, which are probably related to vacancies caused by the implantation. A slightly smaller periodicity is observed in the negative-angle fringes for the $\mathrm{As}^{+}$-implanted samples, evidence of a thicker region of damage in comparison to the $\mathrm{P}^{+}$-implanted samples. An annealing temperature of $600{ }^{\circ} \mathrm{C}$ is sufficient to relieve most of the expansive strain in both sets of samples. After annealing at $700{ }^{\circ} \mathrm{C}$, the DCXRD spectra appear similar to those of the unimplanted samples. The broader full width at half maximum of the main peak is indicative of residual defects in the material.

Figure 2 shows evolution of the mobility $\mu_{\text {eff }}$, the sheet carrier concentration $n_{s}$, and the sheet resistance $R_{s}$, with varying annealing temperature, determined from Hall-effect measurements. The corresponding values in an unimplanted semi-insulating InP wafer are approximately $2000 \mathrm{~cm}^{2} \mathrm{~V}^{-1}$ $\mathrm{s}^{-1}, 10^{7} \mathrm{~cm}^{-2}$, and $3 \times 10^{8} \Omega / \square$, respectively. The electrical properties of the samples are similar, irrespective of whether they were implanted with $\mathrm{As}^{+}$or $\mathrm{P}^{+}$. After implantation, the



FIG. 2. Mobility (a), sheet carrier concentration (b), and sheet resistance (c) as a function of annealing temperature, for InP implanted with $\mathrm{P}^{+}$and $\mathrm{As}^{+}$ to a dose of $1 \times 10^{16} \mathrm{~cm}^{-2}$.

mobility drops to $180 \mathrm{~cm}^{2} \mathrm{~V}^{-1} \mathrm{~s}^{-1}$ for the $\mathrm{P}^{+}$-implanted sample and $40 \mathrm{~cm}^{2} \mathrm{~V}^{-1} \mathrm{~s}^{-1}$ for the $\mathrm{As}^{+}$-implanted sample; $n_{s}$ increases to $\sim 10^{11} \mathrm{~cm}^{-2}$ and $R_{s}$ drops to $\sim 10^{5} \Omega / \square$ for both $\mathrm{As}^{+}$- and $\mathrm{P}^{+}$-implanted samples. The electrical properties of the "as-implanted" sample, consistent with a material that contains a large number of defects, are not changed significantly by annealing at temperatures below $500^{\circ} \mathrm{C}$. After annealing at $600{ }^{\circ} \mathrm{C}$, the effective mobility has increased to the unimplanted value of $\sim 2000 \mathrm{~cm}^{2} \mathrm{~V}^{-1} \mathrm{~s}^{-1}$, the sheet carrier concentration has peaked at $\sim 10^{14} \mathrm{~cm}^{-2}$, and the sheet resistance has dropped to a minimum of $\sim 20 \Omega / \square$. Annealing at $700{ }^{\circ} \mathrm{C}$ causes the mobility to rise $\sim 1.5$ times above the unimplanted value to $\sim 3000 \mathrm{~cm}^{2} \mathrm{~V}^{-1} \mathrm{~s}^{-1}$. For annealing temperatures above $500^{\circ} \mathrm{C}, n_{s}$ becomes very large and the sheet resistance decreases accordingly, indicating the presence of shallow donorlike levels.

Disruption of the Fe doping sites, whose role in the substrate is to compensate for inevitable shallow donor formation during crystal growth, may have allowed the donors to reactivate and contribute to the large sheet carrier concentration. The presence of this effect is also indicated by the very high-mobility values for annealing at $700{ }^{\circ} \mathrm{C}$. However, the typical $\mathrm{Fe}$ doping concentration is $1 \times 10^{16} \mathrm{~cm}^{-3}$, resulting in a sheet concentration of $1 \times 10^{12} \mathrm{~cm}^{-2}$ in a $1-\mu \mathrm{m}$-thick layer of InP. Thus, even if all the Fe acceptors were deactivated, the maximum increase in $n_{s}$ that could be achieved by this mechanism is of the order of $1 \times 10^{12} \mathrm{~cm}^{-2}$. It can be seen that at annealing temperatures greater than $500{ }^{\circ} \mathrm{C}, n_{s}$ is 

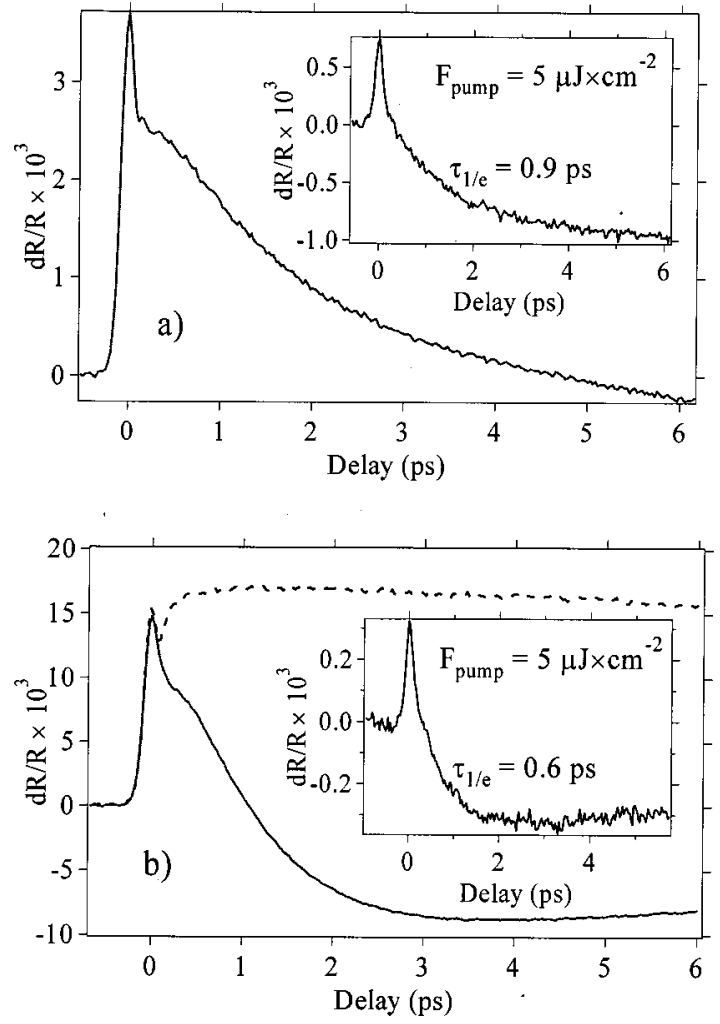

FIG. 3. dR/R signals of $\mathrm{P}^{+}$implanted (a), and $\mathrm{As}^{+}$implanted (b) samples annealed at $700{ }^{\circ} \mathrm{C}$ (unimplanted trace shown by dotted line). $F_{\text {pump }}$ $=50 \mu \mathrm{J} \times \mathrm{cm}^{-2}$ corresponding to an injection density of $\sim 2 \times 10^{18} \mathrm{~cm}^{-3}$. Insets show traces for $F_{\text {pump }}=5 \mu \mathrm{J} \times \mathrm{cm}^{-2}$.

in excess of $10^{13} \mathrm{~cm}^{-2}$. Additionally, the similarity of the Hall-effect data from $\mathrm{As}^{+}$- or $\mathrm{P}^{+}$-implanted samples suggests that the implantation species is not responsible for the annealing-induced changes. Hence, the conclusion that these shallow donorlike levels are created by defects in the crystal structure itself, as a result of the implantation and annealing process. ${ }^{12,13}$

Figure 3 presents the time evolution of normalized differential surface reflectivity (dR/R). Typically, these differential signals originate in the refractive index change $\Delta n$, induced by the optically generated carriers. Since the measurement wavelength $(\lambda=895 \mathrm{~nm})$ is shorter than the band-gap wavelength $\left(\lambda_{\mathrm{BG}}=917 \mathrm{~nm}\right), \Delta n$ and $\mathrm{dR} / \mathrm{R}$ are both positive. Comparing the signal from the unimplanted sample [dashed curve in Fig. 3(b)] with those from implanted samples illustrates the drastic change induced by ion implantation and annealing. The initial peak in all cases corresponds to the pump-probe correlation, after which carriers thermalize, undergo cooling and trapping, and for long delay times (tens of ps-not shown), undergo recombination processes. ${ }^{14,15}$ In the data, taken with a pump fluence of 50 $\mu \mathrm{J} \times \mathrm{cm}^{-2}$, there is a slight "shoulder" visible following the pump-probe correlation peak. This may be attributed to hot carrier dynamics, induced by two-photon absorption at highpump fluences (compare insets for low-fluence excitation). Figure 3 clearly shows that even at high-annealing temperatures traps still exist, in agreement with the DCXRD results.

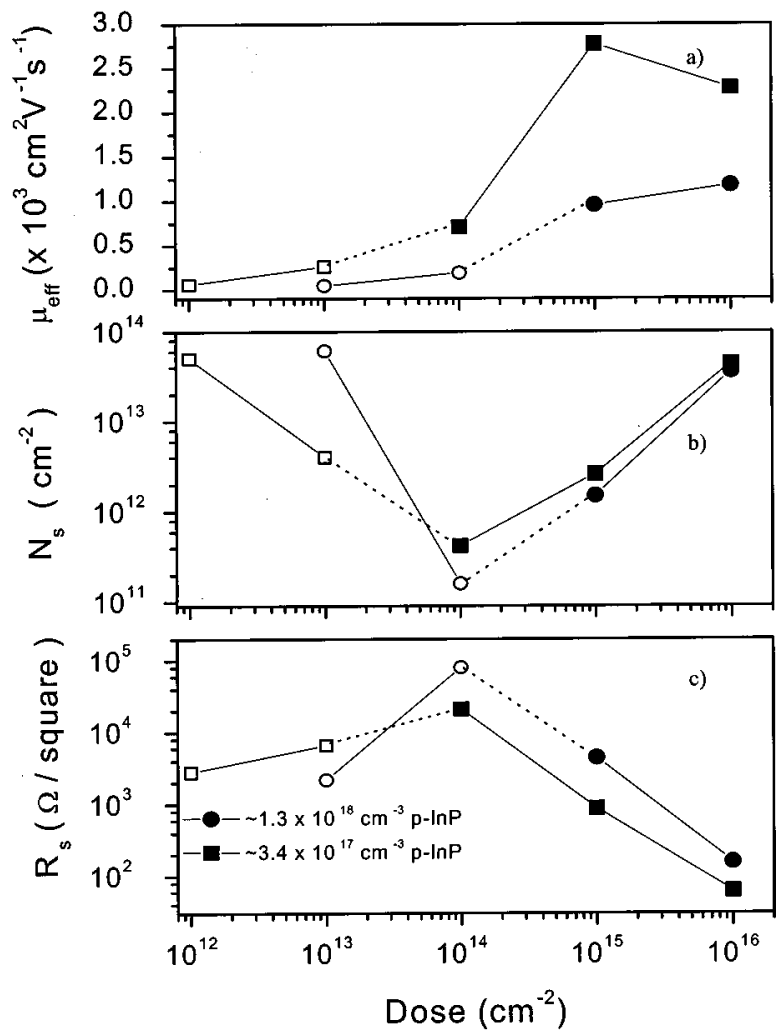

FIG. 4. Mobility (a), sheet carrier concentration (b), and sheet resistance (c) as a function of $\mathrm{P}^{+}$implant dose, for $p$-type $\mathrm{InP}$ with hole concentrations $\sim 3.4 \times 10^{17}$ and $\sim 1.3 \times 10^{18} \mathrm{~cm}^{-3}$. Samples annealed at $600{ }^{\circ} \mathrm{C}$ for $30 \mathrm{~s}$. Open symbols signify $p$ type, and closed symbols signify $n$ type. Joining lines are guides for the eye only.

The data for low-pump fluence $\left(5 \mu \mathrm{J} \times \mathrm{cm}^{-2}\right)$ were normalized after the background values were subtracted, and the delays at which the $\mathrm{dR} / \mathrm{R}$ value fell to $1 / e$ were taken as characteristic trapping related response times. These were $0.9 \mathrm{ps}$ in the $\mathrm{P}^{+}$-implanted case and $0.6 \mathrm{ps}$ in the $\mathrm{As}^{+}$-implanted case.

The results thus far have indicated that it is possible to create a good quality material with a fast response time and good mobility by implanting semi-insulating InP and annealing at high temperatures, but at the expense of low-sheet resistance. Low-sheet resistance is associated with high-dark currents in photodetectors and is therefore considered undesirable. However, such materials may still find application as saturable absorbers for the mode locking of solid-state lasers. Continuing with the main aim of producing fast photodetectors, $p$-type epilayers were used for a round of similar experiments, to see if the donors produced by implantation could be compensated for.

Figure 4 shows the Hall-effect results for $\mathrm{P}^{+}$implantation into two different $p$-type InP samples at doses between $1 \times 10^{12}$ and $1 \times 10^{16} \mathrm{~cm}^{-2}$, and subsequently annealed at $600^{\circ} \mathrm{C}$. Within this range, a critical dose exists at which implantation compensates the $p$-type material. For an acceptor concentration of $\sim 3.4 \times 10^{17} \mathrm{~cm}^{-3}$, an implant dose between $10^{13}$ and $10^{14} \mathrm{~cm}^{-2}$ is required. For an acceptor concentration of $\sim 1.3 \times 10^{18} \mathrm{~cm}^{-3}$, an implant dose between $10^{14}$ and $10^{15} \mathrm{~cm}^{-2}$ is required. Further experiments within this critical range could pinpoint the exact dose for transition 


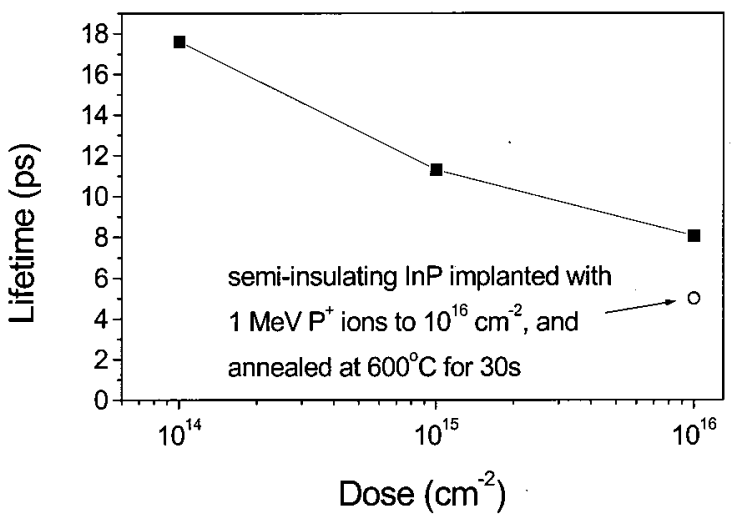

FIG. 5. Plot of time-resolved photoluminescence decay times for $p$-InP $\left(\sim 3.4 \times 10^{17} \mathrm{~cm}^{-3}\right)$ implanted with different doses of $1 \mathrm{MeV} \mathrm{P}{ }^{+}$ions at $200{ }^{\circ} \mathrm{C}$, subsequently annealed by RTA $600^{\circ} \mathrm{C} 30 \mathrm{~s}$.

from $p$ - to $n$-type. This transition dose will also produce the highest-sheet resistance values for implanted $p$-type InP.

Finally, in order to obtain characteristic times for the removal of carriers from the conduction and valence bands (important for ultrafast photodetector applications) we have studied the time-resolved photoluminescence (TRPL) of some samples. Figure 5 shows the TRPL decay time of $\mathrm{P}^{+}$-implanted $p$-type InP $\left(\sim 3.4 \times 10^{17} \mathrm{~cm}^{-3}\right)$ for different ion doses after annealing at $600{ }^{\circ} \mathrm{C}$. The decay times for implanted semi-insulating and $p$-type InP are of a similar magnitude (see Fig. 5). As the ion dose is increased, the carrier lifetime decreases. An implant dose of 1 $\times 10^{14} \mathrm{~cm}^{-2}$, which will compensate the material, results in a photoluminescence decay time of $18 \mathrm{ps}$. The decay time of unimplanted, SI-InP is of the order of a nanosecond, thus implantation results in a several orders of magnitude shortening of the decay time. Defects induced by implantation are known to dramatically increase the trapping efficiency of the material. ${ }^{6}$ Thus, by implanting $p-\mathrm{InP}$, it is possible to produce a material with properties suitable for fast photodetectors.

\section{CONCLUSION}

The electrical, optical and structural changes to semiinsulating $\mathrm{InP}$ as a result of implantation with $\mathrm{As}^{+}$and $\mathrm{P}^{+}$ and subsequent annealing at temperatures between 400 and $700{ }^{\circ} \mathrm{C}$ were investigated using DCXRD, Hall-effect measurements, time-resolved femtosecond differential reflectivity, and photoluminescence. Annealing at high temperatures $\left(700{ }^{\circ} \mathrm{C}\right)$ is required to remove strain and reduce defects introduced during implantation. This also results in a material with high mobility, high-sheet carrier concentration, low resistivity, and short (picosecond) carrier lifetime. $\mathrm{As}^{+}$implantation results in a slightly faster material than $\mathrm{P}^{+}$implantation. By choosing the appropriate implant dose, $p$-type hole concentration, and annealing temperature, $p$-type InP implanted with $\mathrm{P}^{+}$ions could be used for the fabrication of ultrafast photodetectors. For $p$-type InP with a hole concentration of $\sim 10^{17} \mathrm{~cm}^{-3}$ the critical implant dose lies between $10^{13}$ and $10^{14} \mathrm{~cm}^{-2}$, and for a hole concentration of $\sim 10^{18} \mathrm{~cm}^{-3}$, the critical dose is between $10^{14}$ and $10^{15} \mathrm{~cm}^{-2}$, for the samples annealed at $600^{\circ} \mathrm{C}$.

${ }^{1}$ F. W. Smith, A. R. Calawa, C.-L. Chen, M. J. Manfra, and L. J. Mahooney, IEEE Electron Device Lett. 9, 77 (1988).

${ }^{2}$ S. Gupta and J. F. Whitaker, IEEE J. Quantum Electron. 28, 2464 (1992).

${ }^{3}$ M. Kaminska and E. R. Weber, Mater. Sci. Forum 83-87, 1033 (1992).

${ }^{4}$ A. Claverie, F. Namavar, and Z. Lilienthal-Weber, Appl. Phys. Lett. 62, 1271 (1993)

${ }^{5}$ A. Krotkus, S. Marcinkevicius, J. Jasinski, M. Kaminska, H. H. Tan, and C. Jagadish, Appl. Phys. Lett. 66, 3304 (1995).

${ }^{6}$ C. Jagadish, H. H. Tan, A. Krotkus, S. Marcinkevicius, K. P. Korona, and M. Kaminska, Appl. Phys. Lett. 68, 2225 (1996).

${ }^{7}$ D. C. Look, Thin Solid Films 231, 61 (1993).

${ }^{8}$ B. W. Liang, P. Z. Lee, D. W. Shih, and C. W. Tu, Appl. Phys. Lett. 60, 2104 (1992)

${ }^{9}$ W. M. Chen, P. Dreszer, A. Prasad, A. Kurpiewski, W. Walukiewicz, E. R. Weber, E. Sörman, B. Monemar, B. W. Liang, and C. W. Tu, J. Appl. Phys. 76, 600 (1994).

${ }^{10}$ L. J. Van der Pauw, Philips Res. Rep. 13, 1 (1958).

${ }^{11}$ H. H. Tan, C. Jagadish, K. P. Korona, J. Jasinski, M. Kaminska, R. Viselga, S. Marcinkevicius, and A. Krotkus, IEEE J. Sel. Top. Quantum Electron. 2, 636 (1996).

${ }^{12}$ S. Radautsan, I. Tiginyanu, and N. Pyshnaya, Phys. Status Solidi A 108, K59 (1988).

${ }^{13}$ K. Kuriyama, S. Satoh, K. Sakai, and K. Yokoyama, Nucl. Instrum. Methods Phys. Res. B 127/128, 456 (1997).

${ }^{14}$ F. Ganikhanov, G.-R. Lin, W.-C. Chen, C.-S. Chang, and C.-L. Pan, Appl. Phys. Lett. 67, 3465 (1995).

${ }^{15}$ J. Shah, Ultrafast Spectroscopy of Semiconductors and Semiconductor Nanostructures (Springer, Heidelberg, Germany, 1996). 